\title{
O CINEMA BRASILEIRO ENTRE EXCEÇÃO CULTURAL E LIVRE COMÉRCIO
}

\author{
Paulo Borba Casella \\ Professor Associado do Departamento de Direito \\ Internacional da Faculdade de Direito da Universidade \\ de São Paulo'
}

\begin{abstract}
Resumo:
A exceção cultural ao livre comércio, cujo fim seria a defesa do mercado cultural nacional, não pode nem deve ser pretexto para criação de barreiras não tarifárias ou medidas de efeito equivalente. $O$ fenômeno tem de ser analisado sob diversos focos, como o da integração econômica, diversidade cultural e preservação da identidade cultural. A exceção cultural, como instrumento político-jurídico claramente protecionista, gera certo grau de apreensão, já que, além de barreira ao comércio, pode impedir o livre fluxo cultura, tendo-se como pressuposto a falácia da pureza cultura, notadamente desmentida pela riqueza que o contato e fluxo cultural entre diversas civilizações, a História comprova. No que concerne à exceção cultural, devemos ser céticos em relação às politicas nacionais culturais e ter em mente que a exceção cultural carrega implicitamente perigosa escolha de valor.
\end{abstract}

\begin{abstract}
:
The cultural exception to free trade, whose purpose would be the protection of the national cultural market, may not be invoked as an excuse for settingup non-tariff barriers or equivalent measures. The phenomenon must be studied from different points of view, such as economic integration, cultural diversity and protection of cultural identity. The cultural exception, as a political and legal instrument, clearly embodies protectionism, allowing for a certain level of apprehension, not only because it is a barrier to trade, but also could block the free flow of ideas based in the idea of cultural purity, argument belied by the richness that the cultural contact and circulation, between different civilization, is shown to us by History. Concerning cultural exception, it is prudent to be skeptic about national cultural policies and have in mind that the cultural exception entails a dangerous choice of value.
\end{abstract}

Unitermos: cinema brasileiro; livre comércio; direito à cultura; direito comunitário; mercado comum cinematográfico latino-americano.

I. Gostaria de agradecer a valiosa colaboração de Rodrigo Elian Sanclıcz e Tais Muramoto Brigant na atualização normativa $\mathrm{c}$ traduçào da redação original $\mathrm{cm}$ francês, aprescntada $\mathrm{cm}$ scminário na Câmara de Comćrcio Internacional, cm Paris, dezembro de 1996, ponto de partida da atual reflexão, que permaneccra inćdita. 
"A cultura, tal como nós a entendemos hoje, fez sua aparição recentemente, ela é o produto da secularização da religião e da dissolução dos valores tradicionais."

\section{Hannah Arendt, "Criar um meio cultural" (1947)2}

1. O ponto de partida de toda análise que pretenda examinar o papel da exceção cultural em relação ao livre comércio deve ser tentativa de demarcação da noção - mais do que definição - de cultura. Várias outras possibilidades se apresentariam, mas eu proporia considerar a instigante afirmação de Edgar Morin (Encyclopaedia universalis):

"A noção de cultura, em dado momento, engloba todo o fenômeno humano para se opor à natureza, e em outro momento, é o residuo onde se encontra tudo o que não é político, econômico ou religioso..." ${ }^{\text {3. }}$

e, prossegue Morin,

"A cultura se situa no encontro do intelectual e do afetivo, ela seria o equivalente, do ponto de vista social, ao sistema psico-afetivo que estrutura e orienta seus instintos, constrói uma representação ou visão do mundo, opera a osmose entre o real e o imaginário através de símbolos, mitos, normas, ideais, ideologias" 4

Sem cultivar o paradoxo, será necessário notar que, ao contrário do ponto de vista de Morin, quando se trata de exceção cultural, a noção de cultura - a visão sustentada pelos governos, ao menos - terá justamente graus variáveis de conteúdo político, e a esta os dados econômicos não serão estranhos.

O religioso, em nossos dias, será menos facilmente mesclado - e, no entanto, isto poderá sempre acontecer, com conseqüências às vezes desastrosas, das quais Salman Rushdie é somente exemplo recente, entre os mais célebres e os mais tristes, no momento eremita, que corre o risco de, a qualquer instante, se tornar mártir da cultura laica e pluralista e da liberdade de expressão. Atualmente, este escritor foi obrigado a se esconder para manter simultaneamente seu direito de expressão e sua vida. Quantos outros são obrigados a se esconder também, sem que ninguém saiba, podemos sempre nos inquietar...

2. La culture, telle que nous l'entendons aujourd'hui, a fait son apparition récenment, elle est le produit de la sécularisation de la religion et de la dissolution des valeurs traditionelles.

Hannah Arendt, "Creating a cultural atmosphere" (novembro 1947) in La tradition cachée (textos traduzidos do alcmào c do o inglês por Sylvic Curtinc-Denamy; Paris, Cluristian Bourgcois Ed., Bibl. I0/ 18, Trad. Francesa, 1987, pp.171/177)

3. "la notion de culture tantôt englobe tout le phenomène humain pour s'opposer à la nature, tantôt est le résidu où se rassemble tout ce qui n'est ni politique, ni économique, ni religieux ..."

4. "La culture se situe au carrefour même de l'intellectuel et de l'affectif, elle serait l'équivalent, du point de vue social, du système psycho-affectif qui structure et oriente les instincts, construit une répresentation ou vision du monde, opère l'osmose entre le réel et l'imaginaire à travers symboles, mythes. normes, idéaux, illéologies" 
2. Estamos longe de nos encontrar em domínio técnico e neutro, que nos permitiria de bem circunscrever nosso tema e evitar obstáculos - pelo menos do ponto de vista político, econômico ou religioso - e isto somente na pouco verossímil medida em que o jurídico nos permitiria a neutralidade, o que nós deveríamos contestar de forma enérgica desde já. Nós estamos no meio de tema no qual todas estas implicações podem encontrar abrigo, justamente atrás de "disfarce cultural", e alcançar a condução pelo caminho certo, para poder acessar compreensão mais precisa do conteúdo da noção de cultura e do que poderia ser, mais especificamente, o objeto de "exceção cultural".

A possibilidade de separar o 'jurídico' do 'político' é reconhecida por Hans Kelsen somente em sentido técnico - e isto, de forma muito significativa, somente em período tardio da vida deste, posterior à II Guerra Mundial ${ }^{5}$

3. $\mathrm{O}$ aspecto seguinte que mereceria algumas precisões seria a exata configuração de qual pode ser o 'ponto de vista brasileiro' a respeito da matéria de exceção cultural e, além deste, como e em que medida este poderia ser situado no contexto do Mercosul. Significa que não há, ao menos no momento, ao meu conhecimento, a possibilidade de circunscrever a extensão e o conteúdo da exceção cultural no Mercosul, considerando a falta de política cultural comum.

A consolidação de 'concepção cultural' do Mercosul poderia justamente nos oferecer seu lado mais estável e mais durável: a política muda a cada eleição, enquanto a cultura não o faz antes de cada geração...

O Mercosul, o Mercado Comum do Sul, foi criado entre a Argentina, o Brasil, o Paraguai e o Uruguai', de acordo com as bases do Tratado de Assunção, de 26 de março de 1991, reafirmado pelo Protocolo de Ouro Preto, datado de 17 de dezembro de 1994. Este último encerra o período de transição ${ }^{7}$ após o qual, apesar dos extraordinários avanços econômicos e políticos, sem esquecer as não menos surpreendentes tergiversações institucionais e legais, continua, ainda, em ampla escala, zona de livre comércio, com elementos de união aduaneira. Esta, que não sem alguma dose de boa vontade, pretende-se seja união aduaneira, da qual o resultado, até atingir

5. Hans Kelsen, 'On Interpretation', in The Law of the United Nations: a critical analysis of its fundamental problems; Ncw York, F.A. Pracger Inc., Ist. cd., 1950; reprint, 1951), verbis: "Separation of" law from politics in the presentation of national or international problems is possible in so far as law is not an end in itself, but a means, or what amounts to the same, a specific social technique for the achievement of ends determined by politcs. (...) 'Juristic' in contradistinction to 'political' has the connotation of 'technical'"

6. Atualmente comprecndendo, além dos quatro referidos, ainda dois Estados associados, o Chile c a Bolivia, que assinaram sucessivamente Acordos de Associação com o Mercosul.

7. O periodo de transição do Mercosul se encerrou $\mathrm{cm} 31$ de dezembro de 1994. Zona de livrc intercâmbio, uniào aduancira incompleta, dois periodos sucessivos de cinco anos cada, ocorrendo desde I" de janciro de 1995, devem pavimentar a via para a completa rcalização de mercado comum, após 3 I de dezembro de 2005 . 
o início de um mercado comum, continua de forma considerável, a ser feito ${ }^{x}$ Será preciso esperar o fim da crise argentina e das incertezas atuais do Uruguai para dar continuidade a este esforço de integração regional.

Somente sobre alguns aspectos pontuais que será possível situar o "ponto de vista Mercosul' - suficiente em matéria de políticas comuns, comerciais ou outras, de forma insuficiente (em suma, muito pouco) em matéria de direito da concorrência, assim como em matéria de proteção dos consumidores e ainda menos em matéria de exceção cultural.

Posição Mercosul em matéria de exceção cultural será provisória - o que não exclui a possibilidade de futura adoção de políticas culturais comuns. No momento, esta tentativa de aproximação terá caráter de dedução estritamente incidental, a partir do ponto de vista brasileiro.

No entanto, é necessário não esquecer o papel estratégico que pode exercer a cultura na consolidação de 'identidade do Mercosul': distanciada das ligações estritamente comerciais, a Europa continua, de forma considerável, por mais que nós tentemos compreendê-la, antes de tudo a noção cultural; somente a partir das diferenças nacionais que poderemos talvez considerar a Europa como um todo" $O$ fato de não compreender esta nuança fundamental entre o político e o cultural dá ensejo a enormes mal-entendidos!

4. O ponto de vista brasileiro, em si, não será orgânico, e tampouco lógico" a partir de perspectiva político-institucional. O que significa que não será

8. Várias tentativas de integração se succderam no novo mundo, Casclla, "Integration in the Americas: an overview" (Ycarbook of Europ. Law, v. 16, 1996, Oxford, Clarendon Press, 1997). A questão da continuidade c do aprofundamento se colocam claramente para o Mercosul. Neste sentido, v.: Casclla, "From dispute settlement to jurisdiction? Perspectives for the Mercosul" (in International Trade Law and the GATT/WTO Dispute settlement system, cd. by E.-U. Petcrsmann, Dordrccht, Kluwer, 1997, pp. 553/558).

Entre vários estudos c publicações disponívcis sobrc o Mcrcosul, nós tivemos a ocasião de apresentar nossos trabalhos especialmente cm duas obras: Casclla, Mercosul: exigências e perspectivas - integração e consolidação de espaço econômico (préf. Cclso D. dc A. Mcllo, S. Paulo, LTr Ed., 1996) c Casclla (coord.) et al., Contratos internacionais e direito econômico no MERCOSUL: após o término do periodo de transição (préf. J. Dolinger, S. Paulo, LTr Ed., 1996).

9. Neste sentido, Larry Wolff $\mathrm{cm}$ scu Inventing Eastern Europe: the map of civilization on the Mind of the Enlightenment (Stanford, Stanford Univ. Press, 1994) expõc que as difercnças 'culturais' são bcm mais relevantes que aquelas estritamente politicas: "Alienation is in part a matter of economic disparity. the wealth of Western Europe facing the poverty of Eastern Europe, but such disparity is inevitably clothed in the complex windings of cultural prejudice. The iron curtain is gone, yet the shadow persists."

Do lado Mcrcosul, Gregorio Rccondo nos fala do "desafio cultural do Mercosul" cm sua obra Identidad, integración, creación cultural en America Latina: el desafio del Mercosur (Bucnos Aircs, Ed. de l'UNESCO / Edtrl. de Bclgrano, 1997) e insistc no fato que "no habrá integración economica y politica sin integración cultural"

10. Após se perguntar durante muito tempo a respeito da identidade $\mathrm{c}$ do conteúdo de uma cultura brasileira, desde a história clássica atć os autores mais recentes, o fato de sempre se questionar (scm poder sempre responder) c a miscigcnação das mais variávcis camadas culturais $\mathrm{c}$ ćtnicas scriam justamente os dados dos quais deveriam ser considerados para poder estabelecer o conteúdo de uma "cultura brasilcira" 
sempre fácil compreender a razão - mesmo em se tratando de razões de Estado, que não são e não poderiam ser as mesmas para o conjunto dos simples mortais - que orientaria a escolha do Estado em matéria de cultura"

O ponto de vista brasileiro variará de forma considerável de acordo com a perspectiva adotada para a apresentação da matéria e o tema, objeto da reflexão, dificilmente permitirá a 'neutralidade' de apresentação.

Trata-se de domínio em que pouco foi efetuado e o realizado foi feito muitas vezes aleatoriamente, no sentido de medidas isoladas, tanto tematicamente quanto cronologicamente, apesar de algumas outras medidas isoladas adotadas precedentemente, sobretudo durante a participação direta do Brasil na II Guerra Mundial (1942-45) e durante o período militar (1964-1985).

Em 1932, o Decreto n. 21.240, de 19 de abril, estabelecia, em seu art.12, a obrigação de inserir, em cada programa, filme de caráter cultural, de acordo com os critérios determinados pela Comissão de Censura, e em seu art.13, estipulava a proporção de filmes brasileiros e estrangeiros, que seriam obrigatoriamente inseridos na programação de cada mês.

Em 1939, o Decreto-lei n. 1.949, de 30 de dezembro, tornava obrigatório, pelo seu art. 34, para cada sala de projeção, a exibição de "cada ano, ao menos um filme nacional de curta metragem e um de longa duração"

Em 1946, o Regulamento do Serviço de Censura e Divertimento Público (SCDP), aprovado pelo Decreto n. 20.493, de 24 de janeiro, em seu art. 25 dispunha sobre a obrigação de exibição de "três filmes nacionais, de curta metragem ou de longa duração". Estes filmes deveriam, ainda, ter sido previamente declarados de boa qualidade pelo SCDP.

Em 1951, o Decreto n. 30.179, de 19 de novembro, indicava a proporção que deveria ser observada por "todos os cinemas existentes no território nacional", de um filme brasileiro para cada oito filmes estrangeiros. Algumas mudanças foram introduzidas neste dispositivo legal em 1952 e novamente em 1959.0 art. $1^{\circ}$ do Decreto 47.466, de 22 de dezembro de 1959, continha a obrigação de exibição de filmes brasileiros durante "ao menos, 42 dias por ano"

\footnotetext{
Para lcitores da lingua francesa scria conveniente talvez remeter aos cstudos de Mário Carclli, tais como Cultures croisées: histoire des échanges culturels entre la France et le Brésil de la Découverte aux temps mordernes (préf. de Gilbcrt Durand, Paris, Nathan, 1993) ou cntão France-Brésil: cinq siècles de séduction (fotos de Ivan Lima, Rio de Janciro, Ed. Espaço c Tempo, 1989). Lugar a parte deverá ser rescrvado para o clássico de Fernando de Azevedo, A cultura brasileira: introdução ao estudo da cultura no Brasil (Brasilia, Ed. de l'Un. de Brasilia, 4' ed. rev., 1963), que continua sendo obra de referencia. Vários cstudos notávcis seriam, ainda, lembrados, desde Joào Capistrano de Abreu, Caio Prado Jr., Aurćlio Buarque de Hollanda, atć Darcy Ribciro, com seu O povo brasileiro: a formação e o sentido do Brasil (S. Paulo, Cia. das Letras, $2^{2}$. cd., 1995).

II. O que constitui capitulo a partc, que poderiamos enquadrar sob o titulo de 'diplomacia cultural' tal como a cxamina, de ponto de vista brasilciro Edgard Telles RIBEIRO, $\mathrm{cm}$ sua obra Diplomacia cultural: seu papel na politica externa brasileira (Brasilia, Fund. Alexandre de Gusmão / IPRI, 1989).
} 
Esta proporção aumentou progressivamente (56 dias, em 1963; distribuídos em trimestres, em 1967; até 112 dias por ano, em 1971).

Os dois períodos (1942-1945 e 1964-1985) se destacam de conjunto, no qual as garantias constitucionais de Estado de Direito foram mais ou menos formalmente observadas. Algumas especificações relativas a cada periodo podem ser objeto de ressalvas.

A partir da entrada do Brasil no conflito mundial, em 1942, as forças do eixo, inimigos da pátria, deviam ser combatidas. Como conseqüência, ocorre a proibição de publicar ou fazer circular jornais em alemão, em italiano e em japonês (numerosos antes da guerra), assim como ouvir música ou mesmo falar em público nesses idiomas. A cultura, como circulação de idéias e de informações, deveria ser restringida ao quadro de estratégia de guerra. Sob a égide de tais restrições se encontraram lado a lado, no mesmo limbo, canções folclóricas e populares, como Bach, Mozart, Vivaldi e Verdi. Ao mesmo tempo, a Inglaterra, sofria bombardeios regulares dos aviões nazistas, escutando Beethoven, sem esquecer a distinção entre a aeronáutica alemã que despejava sobre Londres seu poder de fogo e a herança cultural do Ocidente, que justamente era questionada pela guerra e deveria ser resgatada a qualquer preço.

Durante o período militar no Brasil, (do golpe de Estado de 31 de março de 1964, que reforçou suas afrontas ao Estado de Direito por volta de 1968, até a redemocratização a partir do fim dos anos 1970, tendo tornado formalmente possível a eleição de presidente civil para a República, em 1985), a adoção mais ou menos oficial ou oficiosa da segurança nacional, como ideologia estatal, permitiu manter à distância, ou mesmo excluir, todas as tentativas de discussão sobre temas que não seriam os considerados adequados nos meios oficiais.

Durante esse período, algumas tentativas foram realizadas, no sentido de estabelecer políticas nacionais em matéria de cinema e de audiovisual, ilustrando exacerbadamente o fenômeno que os economistas denominam "externalidade"

Em 1966 foi criado o Instituto Nacional do Cinema, ou INC, pelo Decretolei n. 43, de 18 de novembro de 1966. Este foi encarregado de "formular e executar a política governamental relativa ao desenvolvimento da indústria cinematográfica brasileira, ao seu fomento cultural è à sua promoção no Exterior". O INC era composto por dois conselhos: um Conselho consultivo, integrado por representantes das "classes cinematográficas', o que significa "os exibidores, os distribuidores, os produtores e os diretores de cinema a critica cinematográfica", e um Conselho deliberativo, integrado por representantes dos diferentes órgãos ministeriais: "Educação e Cultura, Justiça, Indústria e Comércio, Assuntos Estrangeiros, Secretaria de Planificação da Presidência da República, Secretaria de Imprensa e Relações Públicas da Presidência do Banco Central da República" Este conselho, durante nove anos de sua existência, adotou 112 resoluções, entre as quais o aumento das quotas anuais de distribuição dos filmes brasileiros, a obrigação de fazer cópias dos filmes estrangeiros pelos laboratórios brasileiros, e a estandardização dos formulários de controle de exibição.

Resolução de 1979, do Conselho Nacional do Cinema (Res. n. 37 CNCMEC, de 15 de fevereiro de 1979) instaurava, para toda sala de cinema operando 
equipamentos de $35 \mathrm{~mm}$, a obrigação de exibir filmes brasileiros de curta duração, a cada cessão de exibição de filmes estrangeiros de longa duração, e dava precisões a respeito da aplicação desta resolução. Nesta época a proteção estatal à indústria audiovisual brasileira, em alguns aspectos, se tornou caricatural, como no caso da vedação à exibição de cartaz cinematográficco que não fosse criado, produzido e impresso. por brasileiro, de acordo com a Lei n. 6.633, de 28 de abril de 1979.

Por sua vez, a Lei n. 6.281, de 9 de dezembro de 1975 , coloca fim ao Instituto Nacional do Cinema, e atribui suas competências à Embrafilme, a Empresa Brasileira de Filmes S.A.. Esta por sua vez terminará sua inglória carreira no início do Governo Collor (1990-1992).

Para terminar, ao mesmo tempo em que ocorrem as tentativas de estabelecer políticas governamentais, como por exemplo em matéria de cinema e de audiovisual, estas demonstraram excesso de autoridade e falta de visão por parte do Governo: a cada vez e à proporção que aumentavam as cotas de filmes brasileiros, que deveriam ser obrigatoriamente exibidos de forma proporcional, afastava-se o interesse da audiência.

Existe toda uma geração que sofreu artisticamente os efeitos de tais políticas culturais. O direito de escolha, mesmo se continua sendo tantas vezes mal exercido, deve ao menos ser teoricamente preservado ${ }^{12}$

Ao longo dos anos 90, assistimos, felizmente, ao progresso de 'nova onda' do cinema brasileiro, que circula tão bem no País quanto no Exterior, com prêmios internacionais, tais como Veneza, Cannes, e, não fosse o desavergonhado protecionismo local, correriam o risco de chegar a premiações em Hollywood, com menção especial para Central do Brasil e Abril Despedaçado, de Moreira Salles: Fernanda Montenegro recebe o Urso de Ouro em Berlim, em 1997, enquanto, no mais recente, Rodrigo Santoro mostra quanto pode ir longe sua carreira.

Esta 'nova onda' se coaduna com a nova política nacional de cinema, expressa através da criação do Conselho Superior do Cinema e da Agência Nacional do Cinema - Ancine -, criada pela Medida Provisória n. 2.228, de 6 de setembro de 2001. Por seu turno, o Decreto n. 4.121, de 7 de fevereiro de 2002, é claro ao afirmar serem objetivos da Ancine:

"garantir a participação diversificada de obras cinematográficas $e$ videofonográficas estrangeiras no mercado brasileiro;

garantir a participação das obras cinematográficas e videofonográficas de produção nacional em todos os segmentos do mercado interno e estimulá-la no mercado externo" (art. $2^{\circ}$, VIII e IX).

5. Não se trata, ao meu ver, de revisar as polílicas de Estado em matéria cultural somente na medida em que estas poderiam atingir a livre circulação de bens c

12. Pascal Bruckner, La temtation de l'innocence (Paris, Grasset, 1995) obscrva primciro (p.17) " fraqueza e o medo são inerentes à liberdade" e $\mathrm{cm}$ seguida (p.113): "Nós sabemos desde Flaubert, a besteira é ama das formas alo infinito" 
de serviços: em outras palavras, somente na medida em que se colocam a dimensão ou os efeitos político-econômicos de uma política cultural ${ }^{13}$.

Desse modo, a atividade das salas de cinema se encontrava limitada, não por escolhas da audiência, mas por razões tais como o respeito das cotas de filmes, para escapar às sanções administrativas e às multas. Com o mesmo objetivo, a obrigação de serem feitas, no Brasil, por laboratórios brasileiros, cópias de filmes, tiveram resultados muito duvidosos, para não dizer mais. Estas medidas tiveram conseqüências sobre a liberdade de circulação dos bens e dos serviços.

Tal revisão seria no mínimo tão longa quanto desprovida de interesse e deixaria tristes lembranças, como subproduto de herança autoritária que teve como resultado exatamente o contrário do desejável, com os espectadores que se afastavam, cada vez mais, do cinema nacional que se tentava impor, contrariando suas escolhas e seus desejos. Aliás, ainda que de forma mais branda, a fixação de número de dias para a exibição de obras audiovisuais cinematográficas nacionais, sob pena de sanção pecuniária e administrativa continua em vigor através do Decreto n. 4.196, de 11 de abril de 2002.

Tendo afastado tudo o que não seria objeto desta análise, poderíamos nos encontrar privados de objetivo. Contudo, não é o caso, na medida em que, ao menos, alguns dados de base podem ser invocados.

6. De acordo com Alain Riou (1996) ${ }^{14}$ o direito da cultura designa a extensão e a diversidade:

"Direito público, direito privado, direito penal, direito fiscal, direito econômico, direito do mar, a matéria cultural, ela mesma eclética e com fronteiras mal delimitadas, está petrificada por direitos heterogêneos, o que não permite a classificação do direito que o organiza em categoria juridica geral."

13. Malraux, André, La politique, la culture: discours, articles, entretiens (1925-1975) (aprescntados por Janinc Mossuz-Lavau, Paris, Gallimard, Coll. Folio / Essais / Inćdit, lª. cd., 1996);

Marc Fumaroli, L'État culturel: essai sur une religion moderne (Paris, Ed., de Fallois, 1991);

Jacques Rigaud, L'exception culturelle: culture et pouvoirs sous la Ve. République (Paris, Grassct, 1995);

Philippc Urfalino, L'invention de la politique culturelle (Paris, La Documcntation françaisc, 1996): "On explique souvent la spécificité de la politique culturelle française par le poids d'une tradition monarchique d'implication forte de l'Etat dans la vie des arts, par la triple centralisation administrative. politique et culturelle de la société française et par la place éminente et récurrente des arts dans l'identité nationale et dans l'orgueil français. "

VADEMECUM CULTUREL JURIDIQUE (Paris, Dćpartement des Affaires Internationales/Ministèrc de la Culture ct de la Francophonic, 1992).

14. "Droit public, droit privé, droit pénal, droit fiscal, droit économique, droit de la mer, la matière culturelle, elle-même éclectique et aux frontières mal délimitées, est pétrie par des droits hétérogènes, ce qui ne permet pas de classer le droit qui l'organise dans une catégorie juridique générale."

Alain Riou (Le droit de la culture et le droit à la culture (prefácio de Jack Lang, Paris, ESF Ed., |⿰ cd., 1993; $2^{2}$. cd., colocada cm dia c aum., 1996). 
A heterogeneidade das fontes e sua diversidade, assim como a extensão da ação e $o$ alcance da noção, que se estende em vasta gama de atividades e interesses humanos, somente vêm acrescentar desafios a toda tentativa de aproximação sistemática do tema.

Algumas expressões de conteúdo, ou melhor, de um certo ideal de cultura e de seus desdobramentos funcionais - mais do que produtos, tratemos então de 'bens' a propósito de cultura ${ }^{15}$ - poderiam ser examinadas, das quais a primeira com vocação universal, e a segunda de caráter regional, no quadro da experiência de integração mais avançada até o presente.

7. A Declaração Universal dos Direitos do Homem, de 1948, sem ter o conteúdo de carta de direitos positivos, é ao menos a expressão do que poderia ser a opinio juris sive necessitatis da Humanidade. Apesar dos limites à capacidade de assegurar a positivação destes valores, a Declaração de 1948 dispõe, em seu art. 27:

"1. Todo homem tem o direito de participar livremente da vida cultural da comunidade, de fruir as artes e de participar do progresso científico e de seus beneficios.

2. Todo homem tem direito à proteção dos interesses morais e materiais decorrentes de qualquer produção cientifica, literária ou artística da qual seja autor."

Trata-se, já na formulação da Carta de 1948, dos direitos que compreendem simultaneamente a participação de dimensão social, o aproveitamento pessoal e a inserção competitiva; e, também, não menos importantes, os efeitos patrimoniais que deles resultarão...

8. Ponto de referência regịonal nos é oferecido pela evolução da regulamentação da matéria cultural no contexto europeu, desde a lacônica formulação contida no art. $30^{16}$ do Tratado de Roma, de 1957 - em que havia sido feito alusão somente à

15. Como o fazem tanto a UNESCO quanto a UNIDROIT cm matéria de Convenções internacionais para a proteção de 'bens' culturais. Haveria toda uma análise a ser feita para entender o que ć considerado o 'objeto' de proteção legal.

Dominio suficientemente vasto do Dircito Internacional, poderiamos guardar somente alguns pontos de rcferência, i.a.:

Ignaz Scidl-Hohenveldern, "La protection internationale du patrimoine culturel national (Paris, Rev. gćn. de droit int'l. public, no. 2, 1993); Vicentc Marotta RANGEL, "Objetos culturais: o recente projeto UNIDROIT de Convenção internacional" (in Direito e comércio internacional: tendências e perspectivas - estudos em homenagem a Irineu Strenger, coord. Baptista - Huck - Casclla, São Paulo, Ltr Ed., 1994, pp. 213/220); François Rigaud, "Le commerce des oeuvres d'art dans le Marché commun" (in Études de droit international en honneur de Pierre Lalive, Bâlc, Hclbing \& Lichtcnhahn, 1993, pp. 736 ss.); Riccardo Monaco, La contribution d'UNIDROIT à la protection internationale des biens culturels" in La vente internationale des oeuvres d'art coord. par Picrre Lalivc, Gćnève, 1985, pp. 567 ss.).

16. Numcração atualizada, nos termos do art. 12 do Tratado de Amsterdã, de 1997, sendo a antiga numcração cquivalente ao art. 36 do Tratado de Roma. 

arqueológico"

"proteção do patrimônio nacional de valor artístico, histórico ou até o título XII ${ }^{17}$, Cultura, no Tratado de Roma, do qual o art. 151 18, parágrafo único, estipula:

"1: A Comunidade contribuirá para o desenvolvimento das culturas dos Estados- membros, respeitando a sua diversidade nacional e regional, e pondo simultaneamente em evidência o patrimônio cultural comum."

Os $\$ \$ 2$ ao 5, do mesmo art. 151, título IX do Tratado de Roma, expõem os meandros comunitários para a implantação do nosso tema.

Há notável tensão entre a percepção e a avaliação de herança cultural comum de um lado e por outro o esforço de manutenção das diversidades nacionais e regionais.

O principio da subsidiaridade, ainda menos do que em outras áreas, se coloca pouco claramente quando se trata de favorecer a União em relação, i.a., à "conservação e salvaguarda do patrimônio cultural de importância européia". Aquele que terá a competência para situar este patamar europeu de importância do patrimônio cultural, terá a escolha entre os eleitos e os rejeitados, poderá julgar aquilo que deverá ser conservado, financiado etc. e aquilo que deverá tentar viver por seus próprios meios...

Caberá, justamente, atentar para o modo como se há de fazer a implantação das políticàs comunitárias em matéria cultural ${ }^{19}$

9. No âmbito regional, o Brasil faz parte do Acorde para a criação do Mercado Comum Cinematográlico Latino-Americano, assinado cm Caracas, $\mathrm{cm}$ II de novembro de $1989^{20}$ Este acordo contempla poucas disposições para a criaçĩo deste mercado comum, sendo conseqüentemente muito frágil e embrionário.

$\mathrm{O}$ instrumento mais relevante para a efetivação de verdadeiro mercado comum contemplado nesse acordo é a equiparação das obras cinematográficas dos países-membros à categoria de nacional, gozando assim as obras cinematográficas dos demais signatários do Acordo de todos beneficios e direitos conferidos às obras cinematográficas nacionais, como espaço para exibição, cotas de exibição e demais prerrogativas, excetuando porém os incentivos financeiros governamentais. Assim, as obras cinematográficas produzidas nos demais países-membros não desfrutam

17. Numcraçào atualizada, nos termos do art. 12 do Tratado de Amsterdã, de 1997, scndo a antiga numcração equivalentc ao título IX do Tratado de Roma.

18. Numeração atualizada, nos termos do art:12 do Tratado de Amsterdã, de 1997, sendo a antiga numcração cquivalentc ao art. 128 do Tratado de Roma.

19. Le droit communautaire de la culture (vários autores) (Paris, Mission des Affaires Europćcnncs / Ministère de la Culture ct de la Francophonic, 1993)

20. Promulgado por meio do Decreto n. 2.168, de 3 de setembro de 1998. 
dos beneficios concedidos aos filmes brasileiros pela Lei n. 8.685 , de 20 de julho de 1993, bem como os filmes brasileiros não gozam dos mecanismos de fomento financeiro concedidos pelos demais países-membros às suas obras cinematográficas nacionais.

preâmbulo do acordo:

Interessante é a visão dos signatários, acerca do tema, expressa no

"Conscientes de que a atividade cinematográfica deve contribuir para o desenvolvimento cultural e para sua identidade"

E continua no seu art. $1^{\circ}$ :

"(....) com a finalidade de ampliar as possibilidades de mercado e de preservar os laços de unidade cultural entre os povos ibero-americanos e do Caribe."

Destaca-se, ao menos como intenção, a importância da atuação política para consolidação de identidade cultural. Caso emblemático, na constituição de diversos Estados nacionais é a uniformização lingüística, ou seja, o Estado não surgiu devido à prévia existência de forte identidade cultural de um povo, expressa previamente em unidade lingüística, mas através da unificação política se acentuaram os laços culturais, que culminam, na maioria dos casos, em uniformização lingüística, baseada na elevação à categoria de "língua oficial" de um dialeto ou expressão linguística local, como o toscano em relação ao padrão de língua culta, no caso da Itália ${ }^{2 !}$

Assim a idéia de pureza cultural não passa de ficção; ficção esta que alimenta sectarismos e barreiras ao livre fluxo cultural. A análise desmistificada do assunto, coloca as barreiras "culturais" ligadas de forma atávica à política deliberada de construção de identidades culturais e não à pretensa defesa de "pureza" cultural pré-existente. ${ }^{22}$

21. Não ć de outro modo quc o historiador inglês Eric Hobsbawm analisa a questão, cm suas palavras: "As linguas nacionais são sempre, portanto, construçōes semi-artificiais e, às vezes, virlualmente inventados, como o moderno hebreu. São o oposto do que a mitologia nacionalista pretende que sejanas bases findamentais da cullura nacional e as matrizes da mentalidade nacional. Freqüentemente. essas linguas são tentativas de construir idlioma padronizadlo através da recombinação de multiplicidladle de idiomas realmente falados, os quais são, assim, rebaixados a dialetos - e o inico problema nessa construção é a escolha do dialeto que será a base da lingua homogeneizada e padionizada." Eric Hobsbawn, Nações e nacionalismo descle 1780, programa, mito e realidade (trad. Maria Cclia Paoli c Anna Maria Quirino, Sào Paulo, Paz c Terra, pp. 70-71).

Bencdict Anderson, cm scu clássico, Naçāo e Consciência nacional, sintetiza: "Se é amplamente reconhecido que os Estados-nação são "novos"e "históricos", as naçòes a que eles dão expi essão politica assoman de passado imemorial, e, ainda mais importante, deslizam para futuro ilimitado. A mágica do nacionalismo consiste em transformar o acaso em destino. Podemos dizer; com Debray. "sim, é inteiramente acidental que eu tenha nascido fracês; mas, afinal de contas, a França é eterna." Bencdict Anderson, Naçào e consciência nacional (trad. Lólio Lourcnço de Olivcira, Sào Paulo, Ed. Álica, 1989, pp. 19-20).

22. Um excerto de Danicl Defoc, desnuda a falsidade de qualquer idéia de pureza cultural:

"Thus from a Mixure of all kinds began.

That Het'rogeneous Thing. An Englishman:

In eager Rapes, and furious Lust begot.

Betwixt a Painted Britton and a Scot: 
10. O objetivo destas precedentes menções era de localizar os esförços de colocar sob a forma de direito positivo a proteção da cultura - e isto nos coloca perante o dilema de Jakob Böhme: deve-se financiar, regulamentar e apoiar a cultura? Deve-se trazer a marca da autoridade governamental sem perturbar todo o equilíbrio dos micro - climas suficientemente instáveis, certamente, mas ainda vivos, em vez de os substituir por Ersatz semi-oficiais que se sustentam muito mal? Quem ganha com isso: a mediocridade daqueles que obtêm benefícios, sem se preocupar com a qualidade do produto final.

O paradoxo de Jakob Böhme, como proporia nos fazer pensar, antes de apoiar incondicionalmente estas alianças duvidosas entre Cultura e Poder. Este, sapateiro, pobre, tendo, de seu casamento vários filhos, sempre trabalhando com as suas solas e calçados - se se deve acreditar na tradição, onde este nos é apresentado sob este ângulo - escrevia tratados teológicos de profundidade espantosa. Quando um aristocrata boêmio, que se interessou pelo que Böhme escrevia, quis lhe levar sua ajuda, a abundância financeira aparentemente fez calar a fonte e ele não escreveu mais.

Ora, não seria o caso de sustentar a posição inversa, mas este incidente, si non è vero, è ben trovato, na medida em que se deve ter presente ao espírito que o apoio oficial não é necessariamente a solução para fazer avançar a produção cultural, tampouco para a conservar. Neste sentido, a escolha daqueles que poderão ou deverão receber as contribuições é fundamental: deve-se destacar bem aqueles que deverão se beneficiar.

11. O paradoxo da qualidade e dos modos culturais. Nós somos todos produtos de nossos meios e refletimos necessariamente valores e opiniões que nos foram transmitidos desde nossa infância, ou até mesmo antes, de acordo com a linha de C. G. Jung, sobre os arquétipos do inconsciente coletivo. Mas, neste passo, trata-se de fazer a escolha do padrão de qualidade ao qual deverá ser feita a transferência dos fundos.

Dois exemplos podem permitir ilustrar este ponto de vista: as pinturas do Hôtel de Ville de Paris e a produção cinematográfica no Brasil durante o período militar (1964/1985).

Quando visitamos o Hôtel de Ville de Paris, rapidamente nos falam das pinturas murais que adornam os interiores, tentando nos situar no tempo: enquanto

Whose gend'ring Offspring quickly learnt to bow,

And yoke their Heifers to the Roman Plough:

From whence a Mongrel half-bred Race there came,

With neither Name nor Nation, Speech or Fame.

In whose hot Veins new mixtures quickly ran.

Infus'd betwixt $a$ Saxon and a Danc.

While their Rank daughters, to their Parents just.

Receiv'd all Nations with Promiscuous Lust.

This Nauseous Brood directly did contain

The well-extracted Blood of Englishmen...

Danicl Defoc, The True-Born Englishman 
estourava na França o impressionismo, antes de refletir-se no mundo inteiro, o gosto oficial estava atrasado com relação ao Zeitgeist e tinha escolhido financiar Puvis de Chavannes e outros pintores que respondiam melhor ao gosto oficial de seu tempo, e a estes foi confiada a tarefa de executar as decorações murais do renomado hotel parisiense.

Em outro contexto, o Brasil, após desenvolvimento de produção cinematográfica durante os anos 40-50 até o início dos anos 60, fez seu cinema entrar no vazio. O regime militar, instaurado pelo golpe de Estado de $1^{\circ}$ de abril de 1964 (que haviamos sabiamente escolhido festejar em 31 de março - para evitar a identificação com a brincadeira do "dia da mentira", de uso corrente no País), desejando evitar pessoas politicamente incorretas, trouxe seu apoio - e fundos públicos - para financiar as produções cinematográficas de olímpica mediocridade. Nós sofremos, de maneira catastrófica, os efeitos disso no Brasil, que causou desgastes consideráveis, fazendo tábula rasa de produtores e produções independentes, que nos danificaram uma inteira geração de produção cinematográfica no País.

Dois pontos de referência: entre $O$ pagador de promessas, de Dias Gomes, do início dos anos 60, e $O$ quatrilho - que foi nomeado para participar do Oscar de melhor filme estrangeiro em Hollywood, no ano de 1996 -, temos geração perdida. Em seguida, Central do Brasil também foi nomeado e rejeitado em 2000.

Quando nós não conseguíamos suscitar o interesse das pessoas pela produção local de cinema, foi necessário instituir no Brasil regulamentação de triste lembrança, de acordo com a qual todas as salas de projeção deveriam assegurar certa porcentagem de exibição de filmes nacionais. Esta regulamentação levava certamente à exibição de suplementos nacionais, mas absolutamente nulos, de curtas-metragens, por volta de 10 a 20 minutos, que precediam as sessões dos filmes pelos quais nós tínhamos decidido ir ao cinema. No lugar da publicidade que antecede aos filmes, imagine ver imposta a projeção sobre qualquer coisa, visando proteger a 'identidade cultural nacional' brasileira.

12. Estas más lembranças da minha infância e adolescência no cinema me fazem tomar certas precauções em matéria de casamento entre Poder e Cultura: os resultados são freqüentemente desastrosos e economicamente geram externalidades. São aprendizes de feitiçaria que fazem aparecer forças que em seguida escapam ao seu controle e causam desgastes que não poderíamos ou não saberíamos prever.

Assim como em matéria de casamento entre Poder e Religião: deve-se evitar isto a qualquer preço. A eventual escolha deve ser confiada a cada um. Nós não podemos impor um certo caminho como se fosse o caminho certo. Nós temos maus exemplos em demasia a respeito. Não há necessidade de revê-los para dar-lhes valor.

Curiosamente, o que levantaria violentas objeções e repugnância clara e forte em sociedade laica e democrática, como é o caso em França, em matéria de religião, não é tão percebida em matéria cultural - bem ao contrário. A francofonia, a "conservação e a proteção do patrimônio cultural de importância européia", ou ainda 
a promoção da diversidade cultural são invocadas freqüientemente como desculpas válidas. Não deveríamos nos questionar a respeito? Quais são os limites? Quais são os valores e os conteúdos que queremos proteger?

À evidência, não sou entusiasta do modelo hollywoodiano de filmes de aventura. Mas haverá sempre mais pessoas que se interessarão antes por malfeitos de Sylvester Stallone, Arnold Schwarzenegger, ou, então, Jean Claude Van Damme (para oferecer versão européia do mesmo modelo), do que ao que chamamos sintomaticamente de 'cinema de arte', nos filmes italianos, franceses, alemães, escandinavos ou ingleses.

Seria necessário refletir antes de querer fazer cortes profundos.

13. A integração, sobretudo econômica, seria percebida como imperativo categórico - futuramente inevitável - ou, então, como escolha cultural para o caso onde haveria suficiente entusiasmo para se decidir. Isto nos coloca perante o seguinte paradoxo: fazer enquadrar ao mesmo tempo estruturas economicamente ampliadas, em que a produção e as trocas se fazem cada vez mais em escala mundial ou quase, onde a vida econômica se orienta definitiva e inexoravelmente na direção da modernização, ou, ao menos, na direção da regionalização em blocos supranacionais ou transnacionais, e, de outro lado, a vida cultural orientada para a preservação da diversidade e das particularidades, para não dizer seu salvamento. Nós retomamos hábitos como os patoás, nós reutilizamos roupas como os costumes e nós freqüentamos novamente as festas mercantes - seja por convicção, seja para melhor servir a indústria do turismo.

O direito à proteção da identidade cultural se tornou, portanto, categoria jurídica, como observa Erik Jaime em seu Curso Geral de Direito Internacional Privado na Academia da Haia, versando Identidade cultural e integração: o Direito Internacional Privado Pós-Moderno (1995) ${ }^{23}$

14. Certo grau de apreensão, envolvendo a exceção cultural não deve ser negligenciado, na medida em que por trás das 'razões culturais' podem encontrar abrigo a discriminação, o protecionismo, o nacionalismo, a xenofobia.

Sabiamente, a Corte Européia de Justiça desenvolveu arcabouço jurisprudencial para enfrentar e impedir a proliferação de gama importante e muito

23. Erik JAYME, Identité culturelle et intégration: le droit international privé postmoderne (cours génćral de droit international privé, La Hayc, M. Nijhoff, Rec. des cours, tome 251, 1995, pp. 9/267):

"L'époque postmoderne est caracterisé par le rôle primordial que les individus accordent à leur. identité culturelle, dont les expressions extérienres sont la langue, la religion, les moeturs et les autres traditions à laquelle un fort sentiment de loyauté les lie. (...)

"Parmi les traditions qui caractérisent celte identité figurent également certaines règles de droit, surtout en matière de droit des personnes et de la famille. inspirées souvent de convictions religienses. En outre. la protection des symboles de cette appartenance, des noms caractéristiques, de la langue ou des trésors d'art nationaux, fait partie des droits reconnus par les législations relatives anx droits de l homme et par d'autres actes législatifs." 
variada de medidas discriminatórias, que se escondem atrás de cortina de boas intenções, mas que constituem "medidas de efeito equivalente" à discriminação que oficialmente se acordara eliminar. De modo semelhante, a regulamentação do GATT-OMC nos fala do conjunto de barreiras não-tarifárias e de suas conseqüiências.

As medidas não-tarifárias que criam o risco de anular a colocação em prática das liberdades de circulação no seio da União Européia, se utilizavam freqüentemente de "desculpas" de natureza técnica, lingüística, cultural, invocando padrões de qualidade, a proteção dos consumidores, entre tantos outros nomes possiveis (para não multiplicarmos os exemplos, vamos nos lembrar de Cassis de Dijon, a lei da pureza da cerveja etc...).

15. A preservação dos valores sempre trará riscos, na extensão das conseqüêencias e, emprestando termo do jargão médico, eventuais "efeitos colaterais" que nos colocam perante o desafio de encontrar ponto de equilibrio.

Este antagonismo deve nos fazer ter presente os desafios do momento atual: de um lado, riscos de homogeneização em escala mundial ou ao menos supranacional seguem a integração e a globalização, sobretudo econômica, mas estendendo seus efeitos bem além do âmbito estritamente econômico; de outro lado, nos encontramos perante levantes nacionalistas e xenófobos às vezes assustadores e que aparentam esvaziar de todo o seu sentido a civilização para nos levar à Pré-História - a violência e a lei do mais forte, sem nenhuma máscara -, o que tampouco é desejável.

Em mundo que modifica em velocidade crescente parecerá dificilmente conciliável a pretensão de deter o tempo e o fluxo da produção intelectual - seja esta de boa ou má qualidade - e a livre circulação da informação.

16. A exceção cultural parece carregar implicitamente em si a perigosa escolha de valor, cujas bases e sustentação devem ser questionadas: em que medida haveria valores a proteger, de quem devemos protegê-los e como assegurar esta 'proteção'?

Parece que haverá atribuição de excesso de poder àqucle ou àqucles, pouco importa, a quem será incumbido o dever de escolher o que pode e o que não pode passar pelo controle da exceção cultural - na implementação do "Big Brother" orwelliano, que observa tudo e nos protege de todo perigo. Neste momento, sem duvidar, nós somos já a presa do pior dos perigos, tendo perdido a liberdade, que de acordo com Jan Starobinski, haveria sido inventada somente no século XVIII ${ }^{24}$

Ao longo da História, deixamos, bem ou mal, o paraíso intemporal, para poder acessar o conhecimento do bem e do mal, e, bem ou mal, destronamos os regimes autoritários, não para nos ver sob tutela por 'razões de Estado' que não conhecemos e que nos limitariam o acesso a pontos de vista diferentes daqueles que contariam com o apoio do regime vigente - e isto, para vê-los substituidos freqüientemente por outros 
que parecem igualmente sem interesse. Temos, bem ou mal ainda, estruturado sistemas e tentado manter em pé os freios e contrapesos, os famosos "checks \& balances", para manter sob controle os regimes e os partidos políticos - ainda que tal limite seja exercitado por restrições temporais: a escolha, ainda que por decurso de prazo, para não ter que se submeter à sua reeleição!

Temos assistido ao desenvolvimento dos sistemas mundiais de circulação de informação como dos capitais, dos serviços e mercadorias, apesar dos limites operacionais, dos custos e dos gostos - assim como se desenvolveram e se estruturaram, em escala igualmente internacional, também o crime organizado, o terrorismo, o tráfico das drogas, de brancas e crianças e a poluição do meio ambiente - mas uma vez que nos encontramos aqui, deve-se-nos assegurar, ao menos teoricamente, a possibilidade de se ter acesso.

É justamente a escolha de nos portar como filhos e herdeiros do nosso tempo: seja para o 'bem' como para o 'mal' - mas certamente nós teríamos preferido escolher nós mesmos o que nos convém. Deveríamos recusar a qualquer autoridade, seja esta de vocação temporal ou espiritual, decidir o que nos convém ou-não! Não desejamos ver recolocados em vigor novo modelo de Index librorum prohibitorum, não mais por razões eclesiásticas, mas tendo como base alegações de pureza cultural.

17. Tal pretensão repousa sobre a ilusão de poder parar o tempo! Haveria todo um capítulo a escrever a propósito das civilizações que acreditam poder parar o tempo, enquanto outras acreditam segui-lo, até mesmo ser capazes de "fazer" a História.

Para os seres individualmente como para as civilizações, acreditar na possibilidade de freiar o tempo e o fluxo da história significa se colocar à distância. É bem isto que nós pretendemos?

A própria conscientização nos faz perder tempo ou, nos situando em relação ao tempo, nos temporiza - porque necessitamos de tempo para nos conscientizar -, como faz ver Vladimir Jankélévitch, em O puro e o impuro (1960). O puro, uma vez na história, se tornaria de qualquer modo impuro, mesmo se ficasse só no mundo; e a conscientização é a forma interior ou centrífuga que reveste esta perda espontânea da inocência ${ }^{25}$

Levado para a relatividade geral de destino histórico - para prosseguir com o genial Jankélévitch -, o purista se prende com a força do desespero a uma ficção de eternidade; ele se recusa a durar, mesmo que por um segundo, de se mover, mesmo que um milímetrọ; e ele não quer ver que o purismo, ele mesmo, o gosto exagerado pelo passado, o arcaísmo e o tradicionalismo já são momentos do processo. Momentos tão tardios! Esta impotência se verifica nos mínimos detalhes: por exemplo, o pequeno purismo lingüístico defende desesperadamente a 'pureza' da língua contra o fluxo

25. Vladimir Jankélćvitch, Le pur et l'impur (Paris, Flammarion, 1960)

"Le pur, une fois tombé dans l'histoire, deviendrait de toute façon impur même s'il restait seul au monde; et la prise de conscience est la forme intérieure ou centrifuge que revêt ce déniaisement spontané del'innocence." 
invasor das palavras estrangeiras e dos neologismos, fluxo tão irresistível quanto a evolução vital ela mesma; o purismo artístico da arte pela arte e da poesia pura combate passo a passo a prática invasora e as técnicas utilitárias e a ação prosaica que, continuamente, recomeçam a submergi-lo; esta poesia tão penosamente defendida, reconquistada e, apesar de nossa vigilância, novamente perdida, não é comparável a uma embarcação assentada por todos os lados pelo oceano da prosa? O grande purismo em geral, que é a busca da pureza étnica, se distingue também pela recusa do tempo: mas o tempo não necessita que o purismo diga sim, a vida do purista já o diz por ela mesma de maneira suficientemente eloqüente; esta vida faz mesmo melhor do que o dizer, porque toda nossa evolução, cujo envelhecimento é a orientação qualitativa e a intenção concreta, pode passar por aceitação vivida na duração, para consentimento tácito no futuro. Resistir ao irresistível? ${ }^{26}$

18. Hoje em dia, qual é o sentido de 'identidade cultural nacional', quando o mundo ocidental se encaminha para "monocultura" na qual as diferenças entre o centro e a periferia aumentam progressivamente? Isto se produz, entre outros, por razões que poderíamos chamar, de acordo com Schiller, "o colapso da dimensão temporal" na difusão das tendências e das idéias ${ }^{27}$

Para terminar, mais uma vez, Jankélévitch: "Não, a incompressível temporalidade não se deixa flexionar." ${ }^{2 \times}$

São Paulo, junho de 2002

26. Prosscguc Jankćlćvitch (op.cit.): "Emporté dans la relativité générale d'un destin historique, le puriste s'agrippe avec l'acharnement du désespoir à une fiction d'éternité; il refuse de durer, füt-ce une seconde, de se mouvoir, füt-ce d'un milimètre; et il ne veut pas voir que le purisme lui-même, et le passéisme. et l'archaisme, et le traditionalisme sont déjà des moments du processus. Des moments combien tardifs! Cette impuissance se vérifie dans les moindres détails: par exemple le petit purisme linguistique défend désespérément la 'pureté de la langue contre l'afflux envahissant des mots étrangers et des néologismes, afflux aussi irrésistible que l'évolution vitale elle-même; le purisme artistique de l'art-pour-l'art et de la poésie pure combat pied-à-pied la pratique envahissante et les techniques utilitaires et l'action prosaïque qui continuellement recommencent à le submerger; cette poésie si péniblement défendue, reconquise et, malgré notre vigilance, reperdue, $n$ 'est-elle pas comparable à un radeau assiégé de tous côtés par l'océan de la prose? Le grand purisme en général, qui est le catharisme éthique. se distingue lui aussi par le refus du temps: mais le temps n'a pas besoin que le purisme dise oui, la vie du puriste le dit déjà par elle-même assez éloquemment; cette vie fait même mieux que le dire, car toute notré évolution, dont le vieillissement est l'orientation qualitative et l'intention concrète, peut passer par une acceptation vécue de la durée, pour un consentement tacite au devenir. Résister à l'irrésistible?"

27. H. I. Schiller, Communication and cultural denomination (Ncw York, Whitc Plains, 1976); Mircca Eliadc, Occultisme, sorcellerie et modes culturelles (trad. do inglês para o francês Jcan Malaquais, Paris, Gallimard, "Les cssais" CCVI, ćd. orig. cm ingl., 1976; trad. fr., 1978); Umberto Eco, La recherche de la langue parfaite dans la culture européenne (trad. do italiano para o francês Jcan-Paul Manganaro; préf. de Jacques Le Goff; Paris, Éd. du Scuil, (C) 1994; impr. 1997).

28. "Non. l'incompressible temporalité ne se laisse pas fléchir:" 